\title{
Moderate glucose supply reduces hemolysis during systemic inflammation
}

\author{
Johannes Jägers' \\ Stephan Brauckmann ${ }^{2}$ \\ Michael Kirsch' \\ Katharina \\ Effenberger-Neidnicht ${ }^{1,3}$ \\ 'Institute of Physiological Chemistry, \\ University Hospital Essen, Essen, \\ Germany; ${ }^{2} \mathrm{Clinic}$ for Anesthesiology \\ and Intensive Care, University \\ Hospital Essen, Essen, Germany; \\ ${ }^{3}$ Institute of Physiological Chemistry, \\ University Hospital Essen, Essen, \\ Germany
}

This article was published in the following Dove Press journal: Journal of Inflammation Research

Background: Systemic inflammation alters energy metabolism. A sufficient glucose level, however, is most important for erythrocytes, since erythrocytes rely on glucose as sole source of energy. Damage to erythrocytes leads to hemolysis. Both disorders of glucose metabolism and hemolysis are associated with an increased risk of death. The objective of the study was to investigate the impact of intravenous glucose on hemolysis during systemic inflammation.

Materials and methods: Systemic inflammation was accomplished in male Wistar rats by continuous lipopolysaccharide (LPS) infusion (1 mg LPS/kg and h, $300 \mathrm{~min}$ ). Sham control group rats received Ringer's solution. Glucose was supplied moderately (70 mg glucose/kg and h) or excessively (210 $\mathrm{mg}$ glucose/kg and h) during systemic inflammation. Vital parameters (eg, systemic blood pressure) as well as blood and plasma parameters (eg, concentrations of glucose, lactate and cell-free hemoglobin, and activity of lactate dehydrogenase) were measured hourly. Clot formation was analyzed by thromboelastometry.

Results: Continuous infusion of LPS led to a so-called post-aggression syndrome with disturbed electrolyte homeostasis (hypocalcemia, hyperkalemia, and hypernatremia), changes in hemodynamics (tachycardia and hypertension), and a catabolic metabolism (early hyperglycemia, late hypoglycemia, and lactate formation). It induced severe tissue injury (significant increases in plasma concentrations of transaminases and lactate dehydrogenase), alterations in blood coagulation (disturbed clot formation), and massive hemolysis. Both moderate and excessive glucose supply reduced LPS-induced increase in systemic blood pressure. Excessive but not moderate glucose supply increased blood glucose level and enhanced tissue injury. Glucose supply did not reduce LPS-induced alterations in coagulation, but significantly reduced hemolysis induced by LPS.

Conclusion: Intravenous glucose infusion can diminish LPS-related changes in hemodynamics, glucose metabolism, and, more interestingly, LPS-induced hemolysis. Since cell-free hemoglobin is known to be a predictor for patient's survival, a reduction of hemolysis by $35 \%$ only by the addition of a small amount of glucose is another step to minimize mortality during systemic inflammation.

Keywords: lipopolysaccharide, sepsis, erythrocytes, red blood cells, cell-free hemoglobin, glucose metabolism

\section{Introduction}

Correspondence: Katharina Effenberger-Neidnicht Institute of Physiological Chemistry, University Hospital Essen, Hufelandstraße 55, Essen D-45I22, Germany

Tel +492017234103

Email katharina.effenberger-neidnicht@ uni-due.de

Blood glucose level is tightly regulated in healthy individuals. ${ }^{1,2}$ In situations of critical illness (eg, trauma, burn, or systemic inflammation), however, energy metabolism and glucose homeostasis are dysregulated. ${ }^{1-6}$ The metabolic response to injury and sepsis is often called auto-cannibalism and includes a rapid mobilization of all substrate depots (eg, glycogen) and, accordingly, the loss of muscle mass and functional proteins, body 
fat, and the glucose storage. ${ }^{3-7}$ During systemic inflammation, higher glucose requirement is covered by both increased hepatic glycogenolysis and gluconeogenesis leading to an initial hyperglycemic state. ${ }^{5,6,8}$ However, the glycogen depots are quickly exhausted after some time in case of higher glucose consumption. From this moment onward, glucose supply can only be achieved by an increased gluconeogenesis in the liver (temporary euglycemic phase in metabolic stress response) ${ }^{5,6,8}$ If this possibility of endogenous glucose production is also restricted or if the glucose uptake rate exceeds the rate of glucose production - as it is the case for severe sepsis and inflammation - finally hypoglycemia occurs. $5,6,8$ Clinical studies showed that hypoglycemia or hyperglycemia (defined as malglycemia) is associated with an increased risk of death. ${ }^{9-12}$ In situation of critical illness, glucose as energy source for the brain is replaced almost completely by ketone bodies. ${ }^{6}$ Erythrocytes, however, are dependent on glucose as the sole source of energy (anaerobic glycolysis), ${ }^{13,14}$ even though under catabolic conditions, for a short time, the metabolism of 2,3-diphosphoglycerate to pyruvate and lactate is used for adenosine triphosphate (ATP) synthesis as well. ${ }^{15}$ "Starved" erythrocytes perish and hemoglobin and other cytoplasmic components, eg, lactate dehydrogenase and potassium, are released (so-called hemolysis).${ }^{14}$ Cell-free hemoglobin and heme can contribute to organ dysfunction and death, ${ }^{16-19}$ the pathologic mechanisms include nitric oxide (NO) consumption and local vasoconstriction, oxidative injury to lipid membranes, activation of the transcription factor NF- $\kappa \mathrm{B}$, endothelial injury, as well as iron-driven oxidative inhibition of glucose metabolism. ${ }^{19-22}$ Thus, hemolysis can act as a kind of amplifier of the complex response to an infection or injury ${ }^{23,24}$ and worsen the outcome in patients with sepsis or trauma. ${ }^{16-19} \mathrm{In}$ contrast to other studies, glucose balance was not performed via insulin treatment, ${ }^{9,25,26}$ but via exogenous glucose supply. ${ }^{27-29}$ Blood glucose level should be kept high, especially during hypoglycemia, and consequences such as hemolysis through glucose depletion in erythrocytes should be avoided.

In the present manuscript we wanted to investigate whether lipopolysaccharide (LPS)-induced hemolysis can be prevented or reduced if more glucose was present as a substrate for erythrocytes.

\section{Materials and methods} Chemicals and materials

LPS (from Escherichia coli, serotype 0111:B4) was purchased from Sigma-Aldrich (St. Louis, MO, USA), isoflurane from AbbVie Deutschland (Ludwigshafen, Germany), ketamine 10\% from Ceva (Düsseldorf, Germany), lidocaine (Xylocaine 1\%) from AstraZeneca (Wedel, Germany), medical oxygen from Air Liquide (Düsseldorf, Germany), Ringer's solution from Fresenius Kabi (Bad Homburg, Germany), and $2.0 \mathrm{~mL}$ self-filling arterial samplers containing $80 \mathrm{IU}$ electrolyte-balanced heparin (PICO50) from Radiometer Medical (Brønshøj, Denmark). Portex catheters $(0.58 \mathrm{~mm}$ i.d./0.96 mm o.d.) were obtained from Smith Medical International (Grasbrunn, Germany).

\section{Animals}

Male Wistar rats (390-520 g, from Envigo, formerly Harlan Laboratories, Horst, Netherlands) received human care according to standards of the Federation of European Laboratory Animal Science Association. The experimental procedure was reviewed and approved by the local Animal Care and Use Committee with the permit number Az. 84-02.04.2013.A015 (Landesamt für Natur, Umwelt und Verbraucherschutz Nordrhein-Westfalen, Recklinghausen, Germany). Rats were kept under standardized conditions of temperature $\left(22 \pm 1^{\circ} \mathrm{C}\right)$, humidity $(55 \pm 5 \%)$, and $12-\mathrm{h} / 12-\mathrm{h}$ light/dark cycles (06:00 a.m. light on/06:00 p.m. light off, standard time) with free access to food (ssniff-Spezialdiäten, Soest, Germany) and water.

\section{Anesthesia, analgesia and surgical procedure}

Rats were anesthetized with isoflurane and received ketamine and lidocaine for analgesia as already described. ${ }^{30}$ Afterwards, catheters were inserted in femoral artery and vein and perfused with Ringer's solution to maintain the functionality of the catheters. At the end of the experiment, animals were sacrificed by cardiac incision under deep isoflurane anesthesia.

\section{Experimental groups}

Experiments were performed with overall 40 rats. Sham control group rats received Ringer's solution at a rate of $7 \mathrm{~mL} / \mathrm{kg}$ and $\mathrm{h}$ over a total period of $300 \mathrm{~min}$. Systemic inflammation was accomplished by continuous LPS infusion over a total period of $300 \mathrm{~min}$. Glucose was supplied either moderately or excessively during systemic inflammation simultaneously with the LPS infusion. During moderate glucose supply, rats received LPS in a $1 \%$ solution of glucose $/ \mathrm{kg}$ and $\mathrm{h}$. During excessive glucose supply, rats received LPS in a 3\% solution of glucose/ $\mathrm{kg}$ and $\mathrm{h}$. The following experimental groups were compared: 
- SHAM (sham control group): Ringer's solution, $300 \mathrm{~min}$, $\mathrm{n}=12$ rats

- LPS (lipopolysaccharide group): $1 \mathrm{mg}$ LPS in Ringer's solution/kg and h, $300 \mathrm{~min}, \mathrm{n}=12$ rats

- LPS+MG (LPS moderate glucose group): $1 \mathrm{mg} \mathrm{LPS} / \mathrm{kg}$ and $\mathrm{h}+70 \mathrm{mg}$ glucose $/ \mathrm{kg}$ and h, $300 \mathrm{~min}, \mathrm{n}=8$ rats

- LPS+EG (LPS excessive glucose group): $1 \mathrm{mg} \mathrm{LPS} / \mathrm{kg}$ and $\mathrm{h}+210 \mathrm{mg}$ glucose $/ \mathrm{kg}$ and $\mathrm{h}, 300 \mathrm{~min}, \mathrm{n}=8$ rats

\section{Assessment of vital, blood, and plasma parameters}

Systemic blood pressure, heart rates, and breathing rates were determined in 10 min intervals as already described. ${ }^{30}$ Core temperature was kept constant above $37^{\circ} \mathrm{C}$ with an underlying heated operating table and by covering the rats with aluminum foil.

Blood samples were taken from the femoral artery catheter immediately before starting the LPS infusion ( $\mathrm{T}=0 \mathrm{~min}$ ) and at any further hour ( $\mathrm{T}=60,120,180,240,300 \mathrm{~min})$ using self-filling arterial samplers (containing 80 IU electrolytebalanced heparin). Blood gases, acid-base parameters, hematocrit, electrolytes, as well as glucose and lactate concentrations were assessed with a blood gas analyzer equipped with additional electrodes (ABL 715; Radiometer, Københaven, Denmark). Heparinized blood plasma was obtained from the blood samples by centrifugation. Concentration of cell-free hemoglobin was measured using the spectroscopic Soret band method. Activities of lactate dehydrogenase, aminotransferases, and creatine kinase as well as creatinine concentration were determined with a fully automated clinical chemistry analyzer (Vitalab Selectra E; VWR International, Darmstadt, Germany). For each blood sampling, rats were substituted with $0.3 \mathrm{~mL}$ of Ringer's solution. ${ }^{30}$ At the end of the experiments $(\mathrm{T}=300 \mathrm{~min})$, final blood samples were taken in one-tenth volume of citrate $(3.13 \%)$. Citrate blood plasma was used for thromboelastometry (ROTEM; TEM International, München, Germany). The kinetics of clot formation was analyzed by thromboelastometry using INTEM or EXTEM test and described in numerical parameters. ${ }^{30}$

\section{Data analysis and statistics}

Experiments were performed with 12 rats per group for SHAM and LPS and 8 rats per group for LPS+MG and LPS+EG. The included number of rats was set on empirical basis. Randomization was done by lottery before the start of the study. The data are expressed as mean values \pm standard error of mean, and analyses were carried out using GraphPad Prism 6 (GraphPad Prism Software Onc, San
Diego, CA, USA). All data were tested for normality using the D'Agostino-Pearson omnibus normality test. For all independent variables (vital, blood, and plasma parameters), which were determined to have a Gaussian distribution, comparison among multiple groups was performed using one-way analysis of variance followed by Dunnet's post hoc multiple comparisons test. For those that did not pass the normality test, Kruskal-Wallis test was used for the significance analysis followed by Dunn's correction for multiple comparisons. Differences in parameters over time within each group were determined by repeated-measures one-way analysis of variance (ANOVA). An a priori alpha error $P$ of less than 0.05 was considered statistically significant ( $95 \%$ confidence interval). Outliers were defined using box-and-whiskers plots.

\section{Results}

All rats, both treated and untreated with LPS, survived the whole experimental time of $300 \mathrm{~min}$. Continuous infusion of LPS led to hyperthermia, tachycardia, and tachypnea (Table 1). It affected the systemic blood pressure (acute blood pressure elevation within the first hour and continually high blood pressure after approximately 140 minutes until the end of the experiments; Figure 1), the electrolyte homeostasis (hypocalcemia, hyperkalemia, and hypernatremia; Table 1), and the energy metabolism (lactate formation and metabolic acidosis with compensatory hyperventilation, early hyperglycemia, and finally hypoglycemia; Table 1; Figure 2). Rats treated with LPS also showed severe organ and tissue injury (significant increases in plasma concentrations of transaminases, lactate dehydrogenase, and creatine kinase; Table 1). Furthermore, a significant increase of cell-free hemoglobin could be measured indicating massive hemolysis (Table 1; Figure 1). LPS infusion led to a significant increase of clotting time as well as a significant decrease of maximum clot firmness in comparison to SHAM (Table 2).

Both moderate and excessive glucose supply during systemic inflammation reduced LPS-induced increase in systemic blood pressure (Figure 1). The acute blood pressure elevation within the first hour of LPS infusion as well as the later LPS-related continually high blood pressure was reduced significantly by intravenous infusion of moderate or excessive amounts of glucose. At the end of the experiments, however, a slight drop in systemic blood pressure was noticed for additional glucose supply (Table 1; Figure 1).

Glucose supply also diminished LPS-induced release of hemoglobin from erythrocytes. Hemolysis was reduced significantly 120 minutes after starting of LPS infusion till the end of experiment (Table 1; Figure 1). 
Table I Effect of moderate (MG) and excessive glucose (EG) supply on vital, blood, and plasma parameters ${ }^{\text {a }}$ during systemic inflammation

\begin{tabular}{|c|c|c|c|c|c|}
\hline Parameters & $\begin{array}{l}\text { SHAM } \\
300 \mathrm{~min}\end{array}$ & (0 min) & $\begin{array}{l}\text { Lipopolysaccharide } \\
\text { (LPS) } 300 \mathrm{~min}\end{array}$ & $\begin{array}{l}\text { LPS+MG } \\
300 \mathrm{~min}\end{array}$ & $\begin{array}{l}\text { LPS+EG } \\
300 \mathrm{~min}\end{array}$ \\
\hline Systemic blood pressure (mmHg) & $97 \pm 4$ & $(89 \pm 3)$ & $104 \pm 6^{\text {n.s. vs. SHAM }}$ & $91 \pm 6^{\text {n.s. vs. LPS }}$ & $79 \pm 7^{P}=0.0109$ vs. LPS \\
\hline Heart rate $\left(\mathrm{min}^{-1}\right)$ & $334 \pm 8$ & $(297 \pm 6)$ & $392 \pm 12^{P}=0.0015$ vs. SHAM & $375 \pm 6^{\text {n.s. vs. LPS }}$ & $381 \pm 7^{\text {n.s. vs. LPS }}$ \\
\hline Breathing rate $\left(\mathrm{min}^{-1}\right)$ & $47 \pm 3$ & $(56 \pm 2)$ & 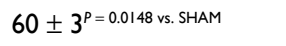 & $59 \pm 3^{\text {n.s. vs. LPS }}$ & $50 \pm 5^{\text {n.s. vs. LPS }}$ \\
\hline Body temperature $\left({ }^{\circ} \mathrm{C}\right)$ & $37.7 \pm 0.1$ & $(37.5 \pm 0.1)$ & $38.1 \pm 0.2^{\text {n.s. vs. SHAM }}$ & $38 . I \pm 0 . I^{\text {n.s. vs. LPS }}$ & $38.1 \pm 0 . I^{\text {n.s. vs. LPS }}$ \\
\hline $\mathbf{p H}$ & $7.26 \pm 0.03$ & $(7.30 \pm 0.01)$ & $7.27 \pm 0.02^{\text {n.s. vs. SHAM }}$ & $7.32 \pm\left. 0.03\right|^{\text {n.s. vs. LPS }}$ & $7.33 \pm\left. 0.03\right|^{\text {n.s. vs. LPS }}$ \\
\hline $\mathrm{pCO}_{2}(\mathrm{mmHg})$ & $49 \pm 2$ & $(45 \pm 1)$ & $37 \pm 2^{P=0.0012 \text { vs. SHAM }}$ & $34 \pm 3^{\text {n.s. vs. LPS }}$ & $33 \pm 2^{\text {n.s. vs. LPS }}$ \\
\hline Base excess (mmol/L) & $-5.1 \pm 1.4$ & $(-3.5 \pm 0.5)$ & $-9.5 \pm 0.7^{P=0.0060 \text { vs. SHAM }}$ & $-8.5 \pm 0.5^{\text {n.s. vs. LPS }}$ & $-8.3 \pm 0.8^{\text {n.s. vs. LPS }}$ \\
\hline $\mathrm{HCO}_{3}{ }^{-}(\mathrm{mmol} / \mathrm{L})$ & $19.9 \pm 1.1$ & $(21.4 \pm 0.4)$ & $16.8 \pm 0.5^{P=0.0144 \text { vs. SHAM }}$ & $17.6 \pm 0.4^{\text {n.s. vs. LPS }}$ & $17.6 \pm 0.6^{\text {n.s. vs. LPS }}$ \\
\hline $\mathrm{pO}_{2}(\mathrm{mmHg})$ & $342 \pm 26$ & $(353 \pm 21)$ & $334 \pm 32^{\text {n.s. vs. SHAM }}$ & $358 \pm 18^{\text {n.s. vs. LPS }}$ & $345 \pm 15^{\text {n.s. vs. LPS }}$ \\
\hline $\mathrm{K}^{+}(\mathrm{mmol} / \mathrm{L})$ & $4.8 \pm 0.1$ & $(5.0 \pm 0.1)$ & $5.1 \pm 0.1^{\text {n.s. vs. SHAM }}$ & $5.2 \pm 0.1^{\text {n.s. vs. LPS }}$ & $5.3 \pm 0.2^{\text {n.s. vs. LPS }}$ \\
\hline $\mathrm{Na}^{+}(\mathrm{mmol} / \mathrm{L})$ & $140 \pm 0$ & $(|4| \pm 0)$ & $142 \pm I^{P=0.0244 \text { vs. SHAM }}$ & $140 \pm I^{\text {n.s. vs. LPS }}$ & $139 \pm I^{P=0.0002 \text { vs. LPS }}$ \\
\hline $\mathrm{Cl}-(\mathrm{mmol} / \mathrm{L})$ & $114 \pm 1$ & $(115 \pm I)$ & $119 \pm I^{P=0.0005 \text { vs. SHAM }}$ & $118 \pm\left.\right|^{\text {n.s. vs. LPS }}$ & $116 \pm I^{\text {n.s. vs. LPS }}$ \\
\hline $\mathrm{Ca}^{2+}(\mathrm{mmol} / \mathrm{L})$ & $1.47 \pm 0.03$ & $(1.53 \pm 0.03)$ & $1.30 \pm 0.05^{P=0.0036 \text { vs. SHAM }}$ & $1.30 \pm 0.03^{\text {n.s. vs. LPS }}$ & $1.29 \pm 0.04^{\text {n.s. vs. LPS }}$ \\
\hline Alanine aminotransferase (U/L) & $77 \pm 16$ & $(59 \pm 10)$ & $336 \pm 64^{P}<0.000$ I vs. SHAM & $181 \pm 30^{\text {n.s. vs. LPS }}$ & $356 \pm 126^{\text {n.s. vs. LPS }}$ \\
\hline Aspartate aminotransferase (U/L) & $98 \pm 11$ & $(68 \pm 5)$ & $427 \pm 6 I^{P=0.0004 \text { vs. SHAM }}$ & $433 \pm 37^{\text {n.s. vs. LPS }}$ & $838 \pm 357^{\text {n.s. vs. LPS }}$ \\
\hline Lactate dehydrogenase (U/L) & $199 \pm 37$ & $(159 \pm 26)$ & $1345 \pm 146^{P}<0.0001$ vs. SHAM & $1326 \pm 150^{\text {n.s. vs. LPS }}$ & $2037 \pm 393^{P=0.0336 \text { vs. LPS }}$ \\
\hline Creatine kinase (U/L) & $148 \pm 33$ & $(364 \pm 55)$ & $550 \pm 83^{P}=0.0006$ vs. SHAM & $586 \pm 103^{\text {n.s. vs. LPS }}$ & $544 \pm 83^{\text {n.s. vs. LPS }}$ \\
\hline Creatinine (mg/dL) & $0.71 \pm 0.10$ & $(0.7 I \pm 0.07)$ & $1.06 \pm 0.10^{\text {n.s. vs. SHAM }}$ & $\mathrm{I} .4 \mathrm{I} \pm 0.2 \mathrm{I}^{\text {n.s. vs. LPS }}$ & $1.52 \pm 0.18^{\text {n.s. vs. LPS }}$ \\
\hline Glucose (mg/dL) & $|5| \pm 8$ & $(147 \pm 4)$ & $46 \pm 6^{P<0.000 I \text { vs. SHAM }}$ & $53 \pm 3^{\text {n.s. vs. LPS }}$ & $97 \pm 17^{P}=0.0014$ vs. LPS \\
\hline Lactate (mmol/L) & $1.0 \pm 0.1$ & $(0.9 \pm 0.1)$ & $2.7 \pm 0.4^{P}<0.000$ Iv. SHAM & $3.0 \pm 0.2^{\text {n.s. vs. LPS }}$ & $3.2 \pm 0.2^{\text {n.s. vs. LPS }}$ \\
\hline Hematocrit (\%) & $37.6 \pm 0.9$ & $(40.7 \pm 0.8)$ & $36.1 \pm 1.3^{\text {n.s. vs. SHAM }}$ & $35.5 \pm 0.9^{\text {n.s. vs. LPS }}$ & $35.2 \pm 0.9^{\text {n.s. vs. LPS }}$ \\
\hline Cell-free hemoglobin ( $\mu \mathrm{mol} / \mathrm{L})$ & $14.4 \pm 3.1$ & $(I I . I \pm 0.8)$ & $43.2 \pm 5.8^{P}<0.0001$ vs. SHAM & $28.1 \pm 2.7^{P}=0.0525$ vs. LPS (n.s.) & $27.2 \pm 3.9^{P}=0.0384$ vs. LPS \\
\hline
\end{tabular}

Notes: aVital parameters, blood gases, electrolytes, plasma enzyme activities, as well as the plasma concentration of creatinine, glucose, lactate, and cell-free hemoglobin of the groups SHAM $(n=12)$, LPS $(n=12)$, LPS $+M G(n=8)$, and LPS+EG $(n=8)$ are shown (mean values \pm standard error of mean) either before the beginning of the LPS infusion (baseline, $T=0 \mathrm{~min}$ ) or at $\mathrm{T}=300 \mathrm{~min}$. Baseline values of the SHAM group were not significantly different from those of the other groups. Lipopolysaccharide (LPS) was infused at a rate of $\mathrm{I} \mathrm{mg/kg}$ and h over a period of $300 \mathrm{~min}$ to induce systemic inflammation in male Wistar rats. Glucose was supplied either moderately (LPS+MG: I mg LPS/kg and h $+70 \mathrm{mg}$ glucose/kg and $\mathrm{h}$ ) or excessively (LPS+EG: I mg LPS/kg and h $+210 \mathrm{mg}$ glucose/kg and h) during systemic inflammation. $\mathrm{n} . \mathrm{s}$. = not significant.

Excessive but not moderate glucose supply increased significantly blood glucose level during systemic inflammation, during early hyperglycemia but even more clearly during final hypoglycemia (Table 1; Figure 2). Moderate glucose supply, however, did not change LPS-induced alterations in blood glucose level.

Additional glucose supply did not beneficially affect LPSrelated functional impairment and tissue injury as indicated by increased lactate formation, electrolyte disturbances, and raised liver and renal function tests (transaminases as well as creatinine and lactate dehydrogenase). On the contrary, plasma concentrations of lactate, lactate dehydrogenase, aspartate aminotransferase, and creatinine were even aggravated, though not always significantly, following excessive glucose supply (Table 1; Figures 1 and 2).

Additional glucose supply did not reduce LPS-induced alterations in the parameters of thromboelastometry (Table 2).

\section{Discussion}

In the present study, we demonstrated for the first time that the cross-talk between glucose and heme metabolism in LPSmediated systemic inflammation could also be bidirectional.
The consequences of sepsis and inflammation are complex and far reaching. ${ }^{31,32}$ Metabolism is converted to catabolism in order to provide all substrates necessary for the immune response and healing process in sufficient quantities. ${ }^{3-7}$ Metabolic disorders, such as hyperglycemia or hypoglycemia, are associated with an increased risk of death. ${ }^{9-12}$ The experimental model of continuous LPS infusion used in the present study reflects most pathophysiological changes known from clinical severe sepsis..$^{30,33,34}$ So, continuous infusion of LPS in our model led to an early hyperglycemic pre-shock state followed by a later hypoglycemic shock state. It induced severe functional impairment and tissue injury.

In addition to metabolic and hemodynamic changes, release of cell-free hemoglobin from erythrocytes (hemolysis) often occurs during systemic inflammation and sepsis. ${ }^{16-19}$ In the present study, we also found massive hemolysis following infusion with LPS. There are many possible mechanisms leading to hemolysis - we recently demonstrated two: in an in vitro study, we could show that LPS as an amphiphilic molecule weakens the membrane of erythrocytes, leading to hemolysis. ${ }^{35,36}$ In another in vivo study, we demonstrated that diminishing of the LPS-induced disseminated intravascular 

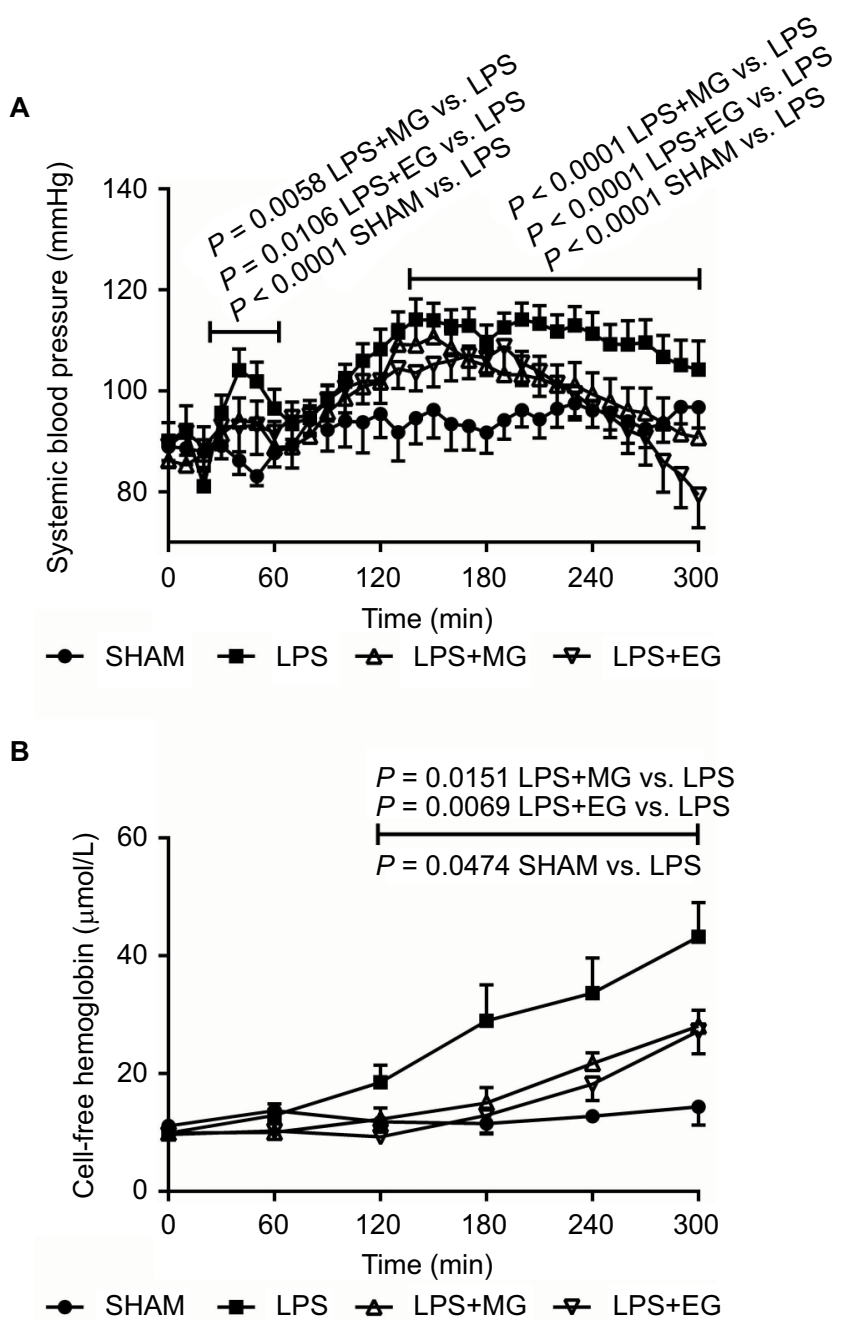

Figure I Effect of moderate (MG) and excessive glucose supply (EG) on systemic blood pressure (A) and plasma concentration of cell-free hemoglobin (B) during systemic inflammation. Lipopolysaccharide (LPS) was infused at a rate of I mg/kg and $\mathrm{h}$ over a period of $300 \mathrm{~min}$ to induce systemic inflammation in male Wistar rats. Glucose was supplied either moderately (LPS+MG: I mg LPS/kg and h + $70 \mathrm{mg}$ glucose/ $/ \mathrm{kg}$ and h) or excessively (LPS+EG: $1 \mathrm{mg}$ LPS/ $\mathrm{kg}$ and h $+210 \mathrm{mg}$ glucose/kg and h) during systemic inflammation. Systemic blood pressure and plasma concentration of cell-free hemoglobin are shown as mean values \pm standard errors of mean.

coagulation is also capable of diminishing hemolysis (Brauckmann, 2017, unpublished). If the metabolism is changed to catabolism, many glucose-dependent organs can resort to other energy sources. For example, the brain uses ketone bodies as energy source when the supply of glucose is restricted ${ }^{6}$. On the other hand, erythrocytes cannot easily change their energy sources, since erythrocytes are imperatively dependent on anaerobic glycolysis. ${ }^{13,14}$ During hypoglycemia, as it could be the case for severe sepsis and inflammation, the erythrocytes are cut off from their energy source. "The energy-less erythrocyte is lost"; it will cease to exist and subsequent hemolysis occurs. ${ }^{14}$

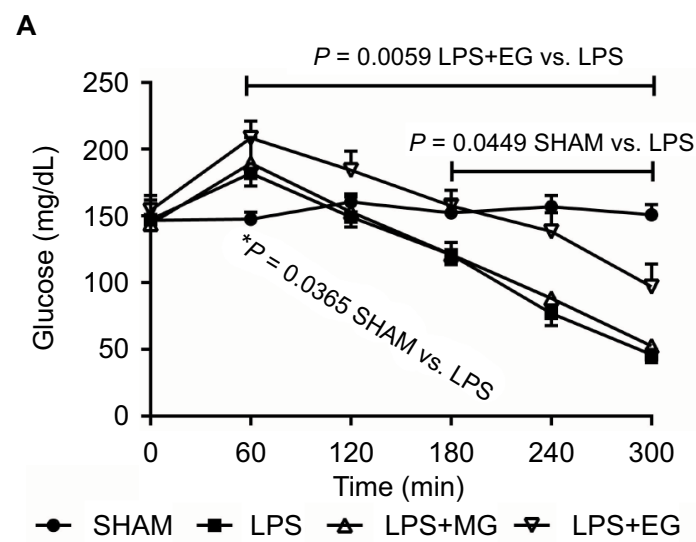

B

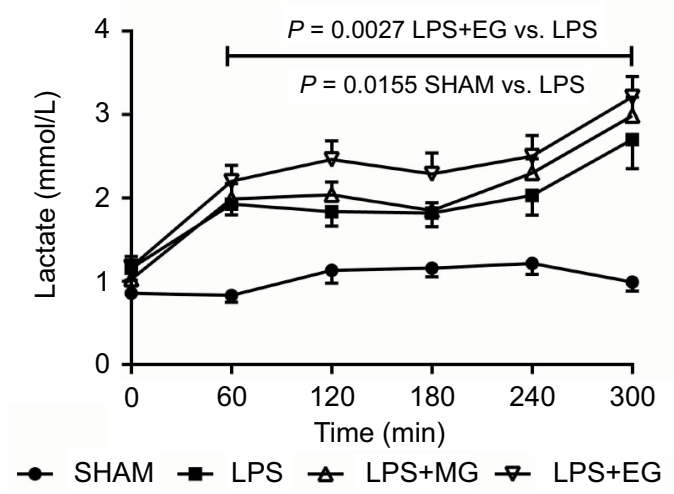

Figure 2 Effect of moderate (MG) and excessive glucose supply (EG) on plasma concentrations of glucose (A) and lactate (B) during systemic inflammation. Lipopolysaccharide (LPS) was infused at a rate of $\mathrm{I} \mathrm{mg} / \mathrm{kg}$ and $\mathrm{h}$ over a period of 300 min to induce systemic inflammation in male Wistar rats. Glucose was supplied either moderately (LPS+MG: I mg LPS/kg and h $+70 \mathrm{mg}$ glucose $/ \mathrm{kg}$ and $\mathrm{h}$ ) or excessively (LPS+EG: I mg LPS/kg and $\mathrm{h}+210 \mathrm{mg}$ glucose/ $\mathrm{kg}$ and $\mathrm{h}$ ) during systemic inflammation. Plasma concentrations of glucose and lactate are shown as mean values \pm standard errors of mean.

Wolfe and coworkers already described that infusion of glucose at a rate of $4 \mathrm{mg}$ glucose $/ \mathrm{kg}$ and min over a total time of $120 \mathrm{~min}$ (corresponds to $240 \mathrm{mg} / \mathrm{kg}$ and $\mathrm{h}$ or cumulatively $480 \mathrm{mg} / \mathrm{kg}$ ) suppressed endogenous gluconeogenesis in healthy volunteers. ${ }^{27}$ In septic patients, glucose infusion at a rate of $4 \mathrm{mg}$ glucose $/ \mathrm{kg}$ and min decreased hepatic glycogenolysis but not gluconeogenesis. ${ }^{27}$ Endogenous glucose production in healthy man was suppressed at a rate of $120 \mathrm{mg}$ glucose $/ \mathrm{kg}$ and h in $120 \mathrm{~min}$ (corresponds to $2 \mathrm{mg}$ glucose $/ \mathrm{kg}$ and $\mathrm{min}$ ) ${ }^{28}$ The absolute degree of suppression was reached at a rate of $240 \mathrm{mg}$ glucose $/ \mathrm{kg}$ and $\mathrm{h}$ in $120 \mathrm{~min} ;{ }^{28}$ at higher doses no further suppression was measurable. ${ }^{27}$ Glucose overload, on the contrary, enhanced hyperglycemia ${ }^{7,37}$ and increased norepinephrine release. ${ }^{38}$ According to the studies of Wolfe et al and due to the fact that glucose overload is detrimental, we used in our study a low dosage (moderate glucose supply: 
Table 2 Effect of moderate (MG) and excessive glucose (EG) supply on parameters of thromboelastometry during systemic inflammation

\begin{tabular}{|c|c|c|c|c|}
\hline Parameters & $\begin{array}{l}\text { SHAM } \\
300 \mathrm{~min}\end{array}$ & $\begin{array}{l}\text { LPS } \\
300 \text { min }\end{array}$ & $\begin{array}{l}\text { LPS+MG } \\
300 \mathrm{~min}\end{array}$ & $\begin{array}{l}\text { LPS+EG } \\
300 \mathrm{~min}\end{array}$ \\
\hline \multicolumn{5}{|l|}{ EXTEM } \\
\hline CT (s) & $38 \pm 4$ & $2691 \pm 435^{P}<0.0001$ vs. SHAM & $2435 \pm 4 \mid 4^{\text {n.s. vs. ve LPS }}$ & $1988 \pm 444^{\text {n.s. vs. LPS }}$ \\
\hline MCF (mm) & $25.0 \pm 1.1$ & $2.5 \pm 0.8^{P<0.0001 \text { vs. SHAM }}$ & $\mathrm{I} .4 \pm 0.8^{\text {n.s. vs. LPS }}$ & $2.8 \pm 1.4^{\text {n.s. vs. LPS }}$ \\
\hline \multicolumn{5}{|l|}{ INTEM } \\
\hline CT (s) & $126 \pm 4$ & $2906 \pm 375^{P<0.0001 \text { vs. SHAM }}$ & $1980 \pm 619^{\text {n.s. vs. LPS }}$ & $1670 \pm 713^{\text {n.s. vs. LPS }}$ \\
\hline MCF (mm) & $19.4 \pm 1.1$ & $0.7 \pm 0.4^{p<0.0001 \text { vs. SHAM }}$ & $2.8 \pm 1.3^{\text {n.s. vs. LPS }}$ & $3.0 \pm 0.9^{\text {n.s. vs. LPS }}$ \\
\hline
\end{tabular}

Notes: ${ }^{2}$ The clotting time (CT) and the maximum clot firmness (MCF) of the groups SHAM $(n=12)$, LPS $(n=12)$, LPS $+M G(n=8)$, and LPS+EG $(n=8)$ are shown $(m e a n$ values \pm standard error of mean) for time point $T=300 \mathrm{~min}$. Lipopolysaccharide (LPS) was infused at a rate of I mg/kg and h over a period of $300 \mathrm{~min}$ to induce systemic inflammation in male Wistar rats. Glucose was supplied either moderately (LPS+MG: I mg LPS/kg and h $+70 \mathrm{mg}$ glucose/kg and h) or excessively (LPS+EG: I mg LPS/kg and $\mathrm{h}+210 \mathrm{mg}$ glucose $/ \mathrm{kg}$ and $\mathrm{h}$ ) during systemic inflammation. $\mathrm{n.s.}=$ not significant.

$70 \mathrm{mg}$ glucose $/ \mathrm{kg}$ and h over a time of $300 \mathrm{~min}$, cumulative: $350 \mathrm{mg}$ glucose $/ \mathrm{kg}$ ) - an effect on the glucose level is not expected - and a high dosage (excessive glucose supply: $210 \mathrm{mg}$ glucose/ $\mathrm{kg}$ and $\mathrm{h}$ over a time of $300 \mathrm{~min}$, cumulative: $1050 \mathrm{mg}$ glucose $/ \mathrm{kg}$ ) - an effect on the glucose level is expected. Indeed, the excessive but not moderate glucose supply had an effect on the plasma concentration of glucose.

Surprisingly, both moderate and excessive glucose supply reduced LPS-induced hemolysis. An indirect effect of glucose as modulator in the inflammation-related activation of coagulation $^{31,39}$ can be excluded, since neither moderate nor excessive glucose supply affected LPS-induced alterations in clot formation kinetics. Ultimately, the additional administration of low glucose seems to protect the erythrocytes from "starvation". It has long been known that a sufficient amount of glucose has a beneficial effect on the quality of stored blood by maintaining acceptable levels of ATP and 2,3-diphosphoglycerate. ${ }^{40-42}$ Exposure of erythrocytes to high glucose concentrations can reduce hemolysis in vitro. ${ }^{43,44}$ Thus, there are many indications that moderate glucose infusion might reduce hemolysis during sepsis or inflammation. A consequential effect of diminished hemolysis, as visible in our study, might be the stabilization of the blood pressure through intravenous glucose supply over a certain period of time. Among others, one explanation could be a lack of the NO-scavenging effect through cell-free heme and hemoglobin. ${ }^{20}$ However, this is rather a result of a reduced hemolysis than an increased glucose concentration. In other words, if less cell-free hemoglobin is released, in turn, less NO would also be trapped, and blood pressure would not increase in consequence of hemolysis. ${ }^{19,20}$ However, at this point, it cannot be excluded that glucose has a direct effect on NO level or even blood pressure.

An excessive accumulation of cell-free heme following hemolysis, moreover, can influence the glucose metabolism by iron-driven oxidative inhibition of the liver glucose6-phosphatase - an enzyme important for endogenous glucose production via gluconeogenesis and glycogenolysis. ${ }^{22}$ Thus, an unidirectional relationship that the accumulation of cell-free hemoglobin or heme affects glucose metabolism during sepsis has already been described by Weis et al. ${ }^{22} \mathrm{We}$ demonstrated that the crosstalk between glucose and heme metabolism could also be bidirectional.

In addition to the reduction of the LPS-induced hemolysis excessive glucose supply, however, might not just increase blood glucose level up to hyperglycemia but also enhance functional impairment and liver injury (increases in plasma alanine aminotransferase, aspartate aminotransferase, and lactate dehydrogenase activity). Liver damage due to large amounts of glucose, as seen in the present study, has already been described by other working groups. ${ }^{45}$ An injured liver is incapable of metabolizing lactate neither back to glucose (gluconeogenesis) nor to carbon dioxide and water. ${ }^{46,47}$ The further increase in plasma lactate, as has been found for excessive glucose supply during systemic inflammation (Figure 2), therefore just reports about an impaired liver function.

The absolute degree of hemolysis reduction was reached by moderate glucose supply; a further reduction following excessive glucose supply was not measurable. It seems that the mechanisms leading to hemolysis during sepsis and systemic inflammation are synergistic or additive. A proportion through the coagulation effect still exists, as is the proportion of the direct membrane effects. Nevertheless, a reduction of hemolysis by $35 \%$ only by the addition of a small amount of glucose is another step to minimize mortality during systemic inflammation.

\section{Disclosure}

The authors report no conflicts of interest in this work. 


\section{References}

1. Van Cromphaut SJ, Vanhorebeek I, Van den Berghe G. Glucose metabolism and insulin resistance in sepsis. Curr Pharm Des. 2008;14(19): 1887-1899.

2. Güemes M, Rahman SA, Hussain K. What is a normal blood glucose? Arch Dis Child. 2016;101(6):596-574.

3. McKechnie S, Walsh T. Metabolic response to injury, fluid and electrolyte balance and shock. In: Garden OJ, Parks RW, editors. Principles and Practice of Surgery. Vol 7. 7th ed. Edinburgh: Elsevier; 2018:3-28.

4. Wanek S, Wolf SE. Metabolic response to injury and role of anabolic hormones. Curr Opin Clin Nutr Metab Care. 2007;10(3):272-277.

5. Hartl WH, Jauch KW. Metabolic self-destruction in critically ill patients: origins, mechanisms and therapeutic principles. Nutrition. 2014;30(3):261-267.

6. Kreymann KG, Wolf M. Die metabolische Antwort auf Trauma und Sepsis [The metabolic response from trauma and sepsis]. IntensivNotfbehandl. 2000;25(1):4-19. German.

7. Michie HR. Metabolism of sepsis and multiple organ failure. World $J$ Surg. 1996;20(4):460-464.

8. Maitra SR, Wojnar MM, Lang CH. Alterations in tissue glucose uptake during the hyperglycemic and hypoglycemic phases of sepsis. Shock. 2000;13(5):379-385.

9. Finfer S, Liu B, Chittock DR, et al; NICE-SUGAR Study Investigators. Hypoglycemia and risk of death in critically ill patients. $N$ Engl J Med. 2012;367(12):1108-1118.

10. Brunner A, Rudiger A. Neurologically intact survival despite severe sepsis-induced hypoglycemia: a case report. Am J Emerg Med. 2011;29(6):696.e1-696.e2.

11. Hammer MJ, Casper C, Gooley TA, O'Donnel PV, Boeckh M, Hirsch IB. The contribution of malglycemia to mortality among allogeneic hematopoietic cell transplant recipients. Biol Blood Marrow Transplant. 2009;15(3):344-351.

12. Krinsley JS. Association between hyperglycemia and increased hospital mortality in a heterogeneous population of critically ill patients. Mayo Clin Proc. 2003;78(12):1471-1478.

13. Schiebler TH, Junqueira LC, Carneiro J. Blut. In: Junqueira LC, Carneiro J, editors. Histologie - Zytologie, Histologie und mikroskopische Anatomie des Menschen [Histology - Cytology, Histology and Microscopic Anatomy of Man]. Vol 4. Berlin: Springer; 1996:314. German.

14. van Wijk R, van Solinge WW. The energy-less red blood cell is lost: erythrocyte enzyme abnormalities of glycolysis. Blood. 2005;106(13):4034 4042

15. Feig SA, Segel GB, Shohet SB, Nathan DG. Energy metabolism in human erythrocytes II: effects of glucose depletion. J Clin Invest. 1972;51(6):1547-1554.

16. Hartmann M, de Groot H. Cell-free hemoglobin: a new player in sepsis pathophysiology. Crit Care Med. 2013;41(8):e186-e189.

17. Adamzik M, Hamburger T, Petrat F, Peters J, de Groot H, Hartmann M. Free hemoglobin concentration in severe sepsis: methods of measurement and prediction of outcome. Critical care. 2012;16(4):R125.

18. Janz DR, Bastarache JA, Peterson JF, et al. Association between cell-free hemoglobin, acetaminophen, and mortality in patients with sepsis: an observational study. Crit Care Med. 2013;41(3):784-790.

19. Janz DR, Ware LB. The role of red blood cells and cell-free hemoglobin in the pathogenesis of ARDS. J Intensive Care. 2015;17(3):20.

20. Rother RP, Bell L, Hillmen P, Gladwin MT. The clinical sequelae of intravascular hemolysis and extravascular plasma hemoglobin: a novel mechanism of human disease. JAMA. 2005;293(13):1653-1662.

21. Winslow RM. Oxygen: the poison is in the dose. Transfusion . 2013;53(2): 424-437.

22. Weis S, Carlos AR, Moita MR, et al. Metabolic adaptation establishes disease tolerance to sepsis. Cell. 2017;169(7):1263-1275. e1214.

23. Dutra FF, Bozza MT. Heme on innate immunity and inflammation. Front Pharmacol. 2014;5:115.

24. Lin XJ, Mei GP, Liu YL, et al. Therapeutic effects of melatonin an heatstroke-induces multiple organ dysfunction syndrome in rats. J Pineal Res. 2011;50(4):436-444.
25. Elke G, Kuhnt E, Ragaller M, et al. Enteral nutrition is associated with improved outcome in patients with severe sepsis. A secondary analysis of the VISEP trial. Med Klin Intensivmed Notfmed. 2013;108(3): 223-233.

26. Brunkhorst FM, Engel C, Bloos F, et al. Intensive insulin therapy and pentastarch resuscitation in severe sepsis. $N$ Engl J Med. 2008;358(2): 125-139.

27. Shaw JH, Klein S, Wolfe RR. Assessment of alanine, urea, and glucose interrelationships in normal subjects and in patients with sepsis with stable isotopic tracers. Surgery. 1985;97(5):557-568.

28. Wolfe RR, Allsop JR, Burke JF. Glucose metabolism in man: responses to intravenous glucose infusion. Metabolism. 1979;28(3):210-220.

29. Wolfe RR, O'Donnell TF Jr, Stone MD, Richmand DA, Burke JF. Investigation of factors determining the optimal glucose infusion rate in total parenteral nutrition. Metabolism. 1980;29(9):892-900.

30. Lansink MO, Görlinger K, Hartmann M, de Groot H, EffenbergerNeidnicht K. Melatonin does not affect disseminated intravascular coagulation but diminishes decreases in platelet count during subacute endotoxaemia in rats. Thromb Res. 2016;139:38-43.

31. Levi M, Nieuwdorp M, van der Poll T, Stroes E. Metabolic modulation of inflammation-induced activation of coagulation. Semin Thromb Hemost. 2008;34(1):26-32.

32. Szabo G, Romics L Jr, Frendl G. Liver in sepsis and systemic inflammatory response syndrome. Clin Liver Dis. 2002;6(4):1045-1066.

33. Brencher L, Oude Lansink M, Effenberger-Neidnicht K. Administration of exogenous melatonin after the onset of systemic inflammation is hardly beneficial. Inflammation. 2017;40(5):1672-1677.

34. Lansink MO, Patyk V, de Groot H, Effenberger-Neidnicht K. Melatonin reduces changes to small intestinal microvasculature during systemic inflammation. J Surg Res. 2017;211:114-125.

35. Brauckmann S, Effenberger-Neidnicht K, de Groot H, et al. Lipopolysaccharide-induced hemolysis: evidence for direct membrane interactions. Sci Rep. 2016;6:35508.

36. Brauckmann S, Effenberger-Neidnicht K, de Groot H, et al. Mechanismen der Lipopolysaccharid-induzierten Hämolyse - Hinweise für eine direkte Zellmembraninteraktion [Mechanisms of lipopolysaccharideinduced hemolysis - evidence for direct cell membrane interaction] Anästh Intensivmed. 2015;56(2):5-6. German.

37. Watanabe Y, Singamsetty S, Zou B, et al. Exogenous glucose administration impairs glucose tolerance and pancreatic insulin secretion during acute sepsis in non-diabetic mice. PLoS One. 2013;8(6):e67716.

38. Nordenström J, Askanazi J, Elwyn DH, et al. Nitrogen balance during total parenteral nutrition: glucose vs. fat. Ann Surg. 1983;197(1): 27-33.

39. McGovern KF, Lascola KM, Smith SA, et al. The effect of hyperglycemia and endotoxemia on coagulation parameters in healthy adult horses. J Vet Intern Med. 2013;27(2):347-353.

40. Bensinger TA, Metro J, Beutler E. In vitro metabolism of packed erythrocytes stored in CPD-adenine. Transfusion. 1975;15(2):135-139.

41. Beutler E. Red Cell Metabolism. Vol 2. Baltimore: Williams \& Wilkins; 1996.

42. Hegedüs E, Harsányi V, Hollán SR. [The effect of increasing glucose in CPD on the quality of stored blood]. Folia Haematol Int Mag Klin Morphol Blutforsch. 1980;107(6):928-933.German [with English abstract].

43. Viskupicova J, Blaskovic D, Galiniak S, et al. Effect of high glucose concentrations on human erythrocytes in vitro. Redox Biol. 2015;5: 381-387.

44. Hendry EB. Delayed hemolysis of human erythrocytes in solutions of glucose. J Gen Physiol. 1951;35(4):605-616.

45. Vanhorebeek I, Ellger B, De Vos R, et al. Tissue-specific glucose toxicity induces mitochondrial damage in a burn injury model of critical illness. Crit Care Med. 2009;37(4):1355-1364.

46. Park R. Lactic acidosis. West J Med. 1980;135(5):418-424.

47. Hussmann B, Lendemans S, de Groot H, Rohrig R. Volume replacement with Ringer-lactate is detrimental in severe hemorrhagic shock but protective in moderate hemorrhagic shock: studies in a rat model. Crit Care. 2014;18(1):R5. 


\section{Publish your work in this journal}

The Journal of Inflammation Research is an international, peer-reviewed open access journal that welcomes laboratory and clinical findings on the molecular basis, cell biology and pharmacology of inflammation including original research, reviews, symposium reports, hypothesis formation and commentaries on: acute/chronic inflammation; mediators of inflammation; cellular processes; molecular mechanisms; pharmacology and novel anti-inflammatory drugs; clinical conditions involving inflammation. The manuscript management system is completely online and includes a very quick and fair peer-review system. Visit http://www.dove press.com/testimonials.php to read real quotes from published authors.

Submit your manuscript here: https://www.dovepress.com/journal-of-inflammation-research-journal 